R. D. Magarey and R. C. Seem

New York State Agricultural Experiment Station, Geneva

\author{
J. M. Russo, J. W. Zack, and K. T. Waight \\ SkyBit, Inc., Bellefonte, PA \\ J. W. Travis \\ Pennsylvania State University, University Park \\ P. V. Oudemans \\ Rutgers University, Chatsworth, NJ
}

\title{
Site-Specific Weather Information Without On-Site Sensors
}

\begin{abstract}
Plant pathologists are well aware of the role weather plays in the epidemiology of many important pathogens (55). In particular, temperature, surface wetness, relative humidity, and sometimes rain are commonly used for disease management (57). The acquisition of on-farm or site-specific weather data can be problematic due to the costs of purchasing and maintaining farmbased automated weather stations (AWSs). Where these AWSs have been lacking, weather data may only be available at spatial and temporal scales too crude for use in site-specific decision making (Fig. 1). This applies especially to the use of forecast weather data, which has potential to convert disease warnings into true disease forecasts. In this article, we will describe the emerging technologies for obtaining site-specific weather data without on-site sensors. We will present a brief history of the development of these technologies, their present limitations, and their prospects for future improvement.
\end{abstract}

\section{From Weather Stations to Spatial Interpolations}

The development of site-specific weather information has been an evolutionary process. Early on, farmers used simple rules of thumb to help determine when disease was imminent. An example from our own research is the 10:10:24 rule of thumb, which helps growers identify weather conditions suitable for downy mildew (28). The 10:10:24 rule states that primary infection occurs with a minimum of 10-mm rainfall, when temperatures are at least $10^{\circ} \mathrm{C}$ with soil wetness for a $24-\mathrm{h}$

Dr. Magarey's address is: 40 Magarey Rd., Coromandel Valley, SA, 5051, Australia; E-mail: rdm5@cornell.edu

Publication no. D-2001-1019-01F

(C) 2001 The American Phytopathological Society period. A similar rule was developed for secondary infection. Later, farmers began to monitor local weather conditions with sheltered manual instruments, such as a hygrothermograph. Over the past 20 years, manual instruments gave way to AWSs. With each generation, the AWSs became more sophisticated, improved in reliability, and dropped in price. Today, AWSs sport solar panels, radio transmission of data, and a variety of agricultural models to convert weather data into a more useful form for decision making (Fig. 2). Even with their steady drop in cost, a full- featured AWS may cost as much as US $\$ 4,000$. The purchase cost and the need for seasonal calibration, regular maintenance, and occasional sensor replacement discourages the use of AWSs in many farming operations. The continued support for their proper operation translates into additional costs and a commitment of time. In addition to the equipment concerns, there is the management of data from the sensor to a decision support system. The collection and transfer of data from field to program can be particularly time-consuming and subject to errors.

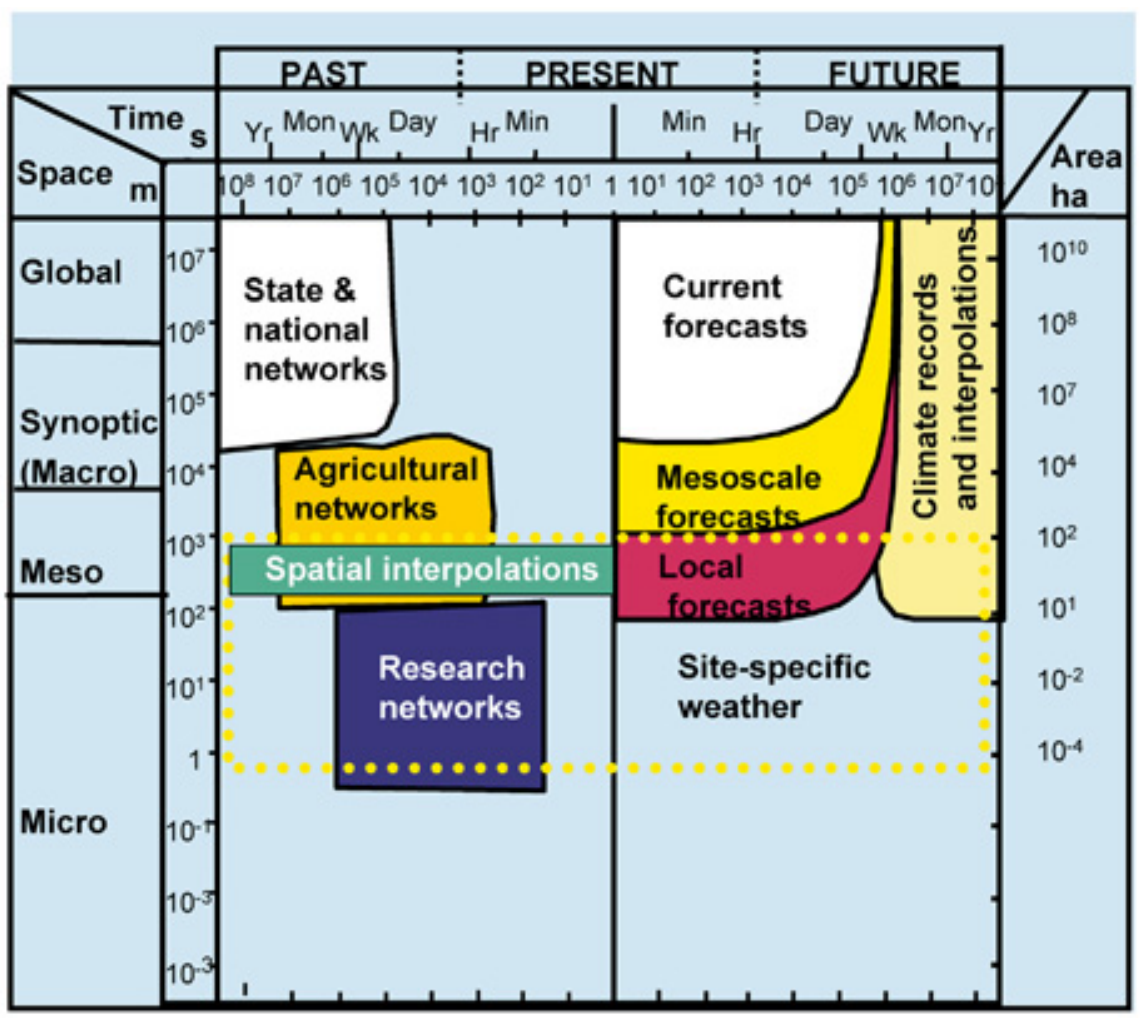

Fig. 1. Spatial and temporal scales for weather information for plant disease management, modified from Seem and Russo (54). 
The cost factor associated with AWSs created two responses. The first is the development of low-cost, automated weather instruments or stand-alone packages. Examples of these units include a single, enclosed temperature, wetness, and/or relative humidity sensor or disease predictor hung in a canopy. Single, automated sensors are capable of storing hourly electronic observations for months. The stored records can be downloaded to a laptop computer.

The second response was to share the costs among many users by creating regional AWS networks. Regional networks $(8,10,58)$ complement the cruder scale national networks. With their higher AWS density in a smaller area, they are a compromise between providing true on-site data and minimizing cost. One of the best examples of a regional AWS network is the 2,000-station Adcon system (Adcon Telemetry, Santa Rosa, CA) in California (58). Phone or radio communications are commonly used to connect individual AWSs in a regional network to a base station or storage node. The Adcon system uses radio transmitters that can be as far as $20 \mathrm{~km}$ from the base station (43). Recorded data are typically accessed from a storage node by either phone or the internet. While an individual AWS within a network may be relatively inexpensive, additional funds are required to store and communicate data from a base station. Bingham et al. (10) investigated central, regional, and local support modes and concluded that the local mode was the most desirable because of lower communication costs. Low-cost AWS and regional networks, while financially attractive to an individual grower, do not remove the commitment of time.

Regional AWS networks are most attractive in areas that have a high concentration of agricultural industries, have a minimal

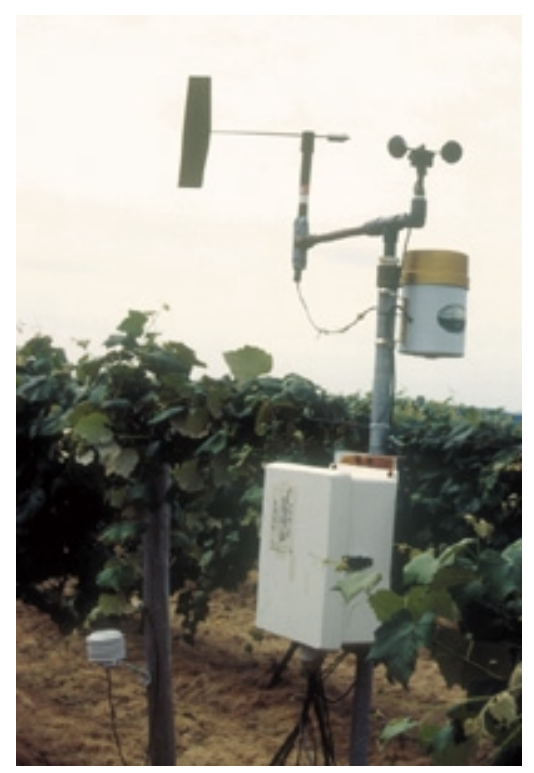

Fig. 2. An automated weather station. (Photo courtesy D. Gadoury) frequency of weather phenomena that interfere with data transmission, and have a favorable terrain. As Kuuseoks et al. (25) point out, topography, direction of prevailing wind, and distance from large bodies of water may be of more importance than simple geographic distance. While a minimum AWS density has yet to be established for substituting network data for an on-site AWS unit, estimates vary from 5 to $30 \mathrm{~km}$ between stations $(18,22)$. These estimates still do not achieve the desired spatial range of $1 \mathrm{~km}$ to $1 \mathrm{~m}$ for on-farm decision making.

About the same time on-site AWSs began to replace manual instruments, analytical solutions were being explored as a tool for creating site-specific data. One popular analytical technique is spatial interpolation. While there are many kinds of spatial in- terpolation, they all share the ability to estimate data for a site having no instruments by mathematically manipulating weather measurements from surrounding stations. The estimated data produced by spatial interpolation are commonly identified as "simulated observations." One example of spatial interpolation is Seem et al.'s (53) use of regression analysis on data from three weather stations to generate simulated observations for 16 farm sites at a $0.1 \mathrm{~km}^{2}$ level across a $320 \mathrm{~km}^{2}$ region. The variables of slope gradient, aspect, elevation, and proximity to ocean and station were used in the analysis. In a comparison with recorded data, an accuracy of 85 to $95 \%$ was obtained for simulated observations of maximum and minimum temperature. In another study, Kuuseoks et al. (25) found that simulated observations

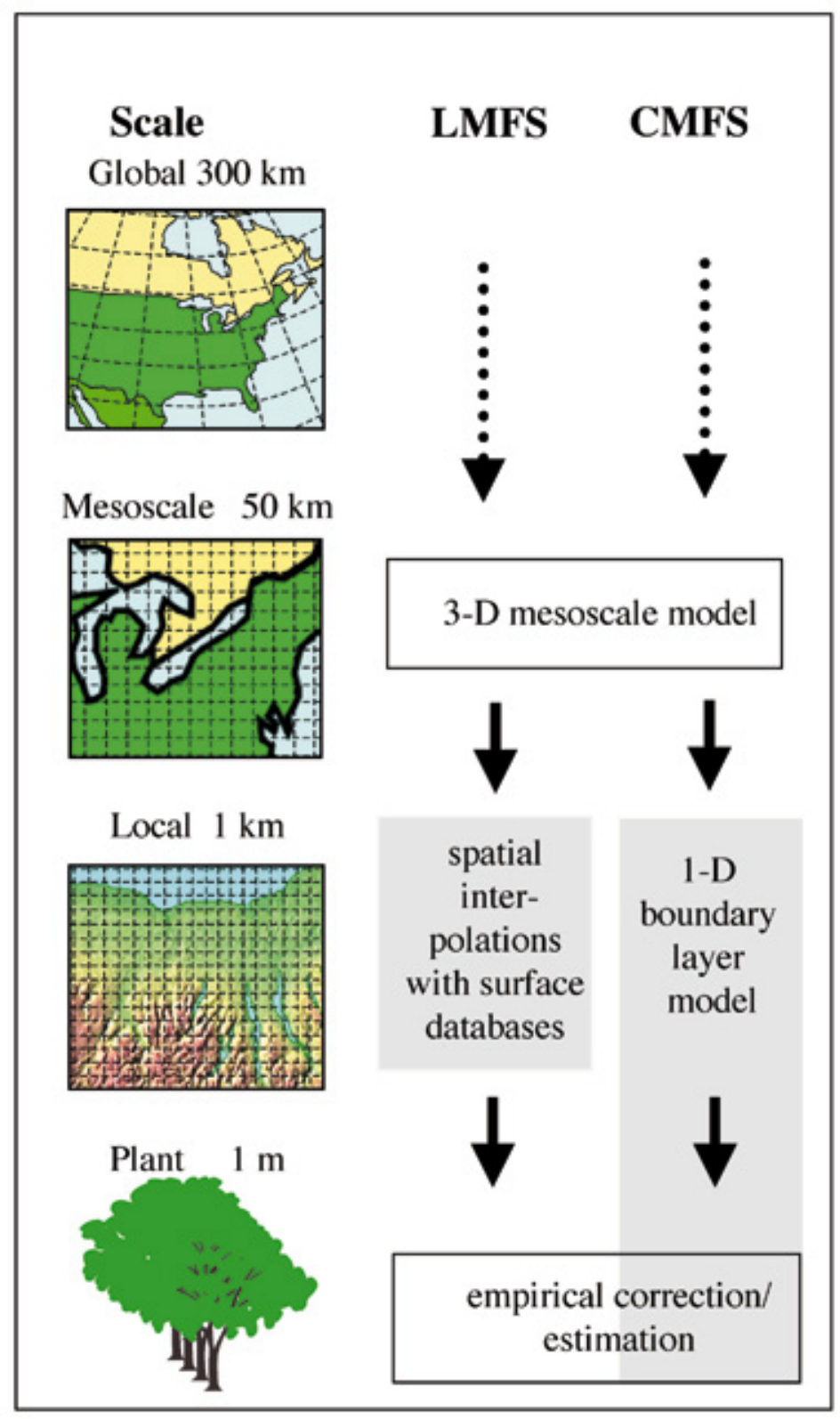

Fig. 3. A comparison of two techniques for creating site-specific forecasts from mesoscale model output (modified after 52). 
improved temperature estimates by an average of $1.8^{\circ} \mathrm{C}$ over simply using the nearest weather station.

The success of spatial interpolation as a tool for simulated observations at the farm level motivated university, government, and commercial ventures to create "high resolution" databases. One company, SkyBit, Inc. (Bellefonte, PA), developed an electronic weather (E-Weather) service to generate site-specific weather data for agriculture and other industries (46). Utilizing raw data from station networks operated by the National Weather Service (NWS), the Federal Aviation Administration (FAA), and the U.S. military, SkyBit's E-Weather Service offers growers a variety of products, which incorporate simulated observations (E-weather Observed) (46). Based on the results of anathe E-Weather Service delivers singlesheet text and graphical products to growers via fax or e-mail. Growers and other users can subscribe to the EWeather Service on a monthly basis.

Many growers find the cost for electronic products, such as those offered by the E-Weather Service, competitive with an on-site AWS. The most appealing aspect to growers is that the product comes ready to use and requires no input on their part. While the generation of site-specific data using analytic techniques is appealing, there are disadvantages. The first is psychological. Since there is no on-site instrument that a user can "touch and hold," the simulated observations are perceived as not being truly representative of their local site. The second important disadvantage is the uncertainties associated with sitespecific weather information to be discussed in detail below. lytic techniques and numerical models,

\section{Site-Specific Forecasts}

The next important development was that of site-specific weather forecasts. Forecast weather data can provide farmers with advanced warning of infection periods and allow them to use protectant fungicides, which are usually cheaper than eradicants. On large farms, several days may be required to apply a treatment, so any lag time in the delivery of weather information and disease forecasts can be crucial. Additionally, forecast data can allow growers to apply a treatment before rain limits machinery access to fields.

In the past, synoptic-scale models were the standard for weather forecasts, but these have fairly coarse resolution (grid sizes $>100 \mathrm{~km}$ ). More recently, however, mesoscale models (33) are being used to generate forecasts at a much higher resolution $(5$ to $50 \mathrm{~km})$. Site-specific forecasts, either at the local or plant scale, can be created by downscaling mesoscale output to a higher spatial scale (52) using techniques such as the Localized Mesoscale Forecast System (LMFS) and the CanopyMesoscale Forecast System (CMFS) (Fig. $3)$.

The LMFS was developed by Kelly et al. (24), who called the system the Model Output Enhancement (MOE) technique. The technique operates by: (i) interpolating upper air forecasts from mesoscale numerical model output to approximately 1 $\mathrm{km}^{2}$; (ii) extrapolating the interpolated data to the surface using theoretical and observed atmospheric processes; and (iii) adjusting the extrapolated surface values with digital terrain data (44). Other surface data also may be used to calibrate the forecasts. With their ability to produce $1 \mathrm{~km}^{2}$ site-specific weather information, these become a viable alternative to weather sta-

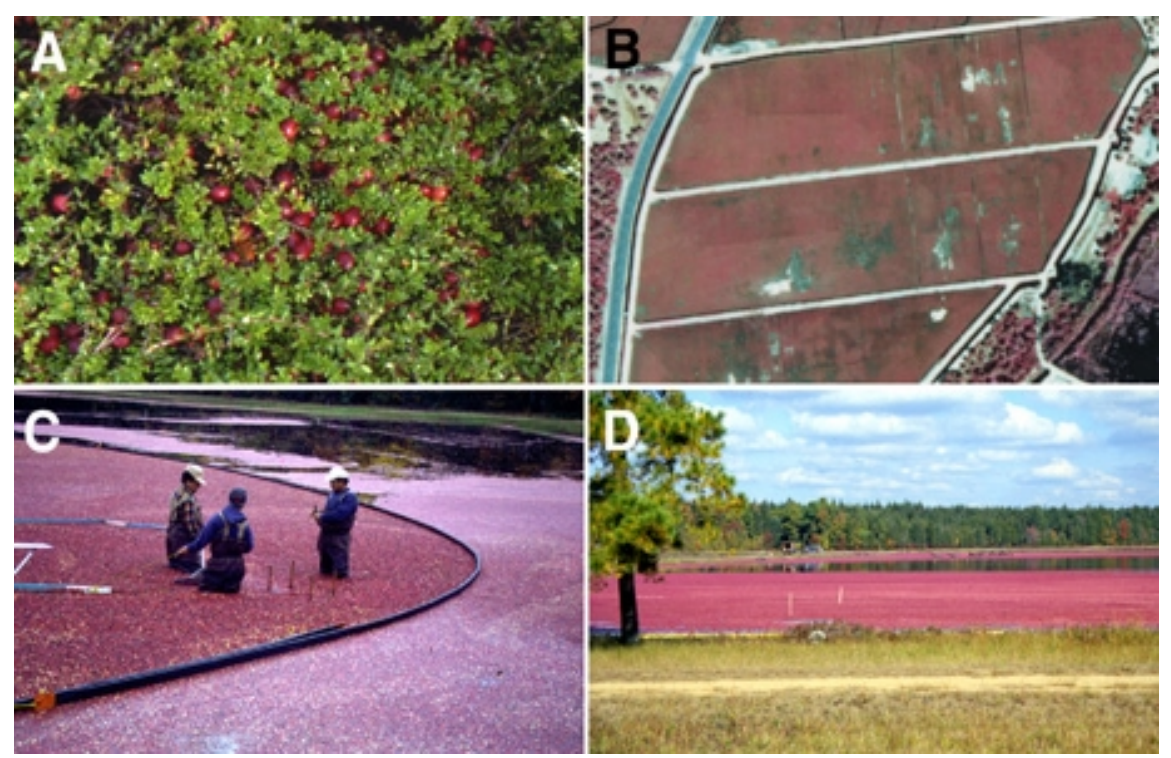

Fig. 4. Cranberry production. A, Cranberry canopy. B, Aerial view of cranberry bogs. $C$, Close up of harvesting operation. D, Cranberry bog flooded for harvest. tion networks. The LMFS is part of the data analysis procedure used to generated forecast products in SkyBit's E-Weather Service (E-Weather Forecast). Some EWeather products such as the hourly product and the IPM Apple Disease Product include both simulated observations and forecasts. We propose the term "sitespecific weather simulator" to describe technologies or analytical techniques that produce site-specific observations and forecasts without on-site instrumentation.

\section{Canopy Microclimate}

Although the LMFS has high utility, it does not provide a specific picture of the plant canopy microclimate. Canopy microclimate may modify environmental conditions greatly compared with a turf surface where most standard weather station measurements are made. For example, Gillespie and Barr (16) found that crop temperature differed considerably from observations made by a proximal weather station. Monteith and Unsworth (35) quote the following figures as typical variation within a field crop: $3^{\circ} \mathrm{C}$ for air temperature, $1 \mathrm{~m} \cdot \mathrm{s}^{-1}$ for wind speed, $0.2 \mathrm{kPa}$ for water vapor pressure, and $400 \mathrm{~W} \cdot \mathrm{m}^{-2}$ for solar radiation. Heilman et al. (20) found a 3 and $2^{\circ} \mathrm{C}$ variation in canopy surface and air temperature, respectively, from the sunlit to the shaded side of a grapevine hedgerow. Plant canopy size has a profound influence upon surface wetness duration. Results of simulations show that wetting periods may be twice as long for a large canopy as for a smaller one (32). In general, canopy microclimates with high leaf densities and poor air circulation are more prone to disease (57).

One approach to a better representation of the canopy microclimate is to run a canopy model from simulated observations to create simulated canopy observations. Anderson et al. (1) used synoptic scale meteorological observations collected from a regional scale weather network to run the Alex (2) model for potatoes. The authors compared predictions made with the BLITCAST disease forecasting system using canopy-collected input to those made with simulated canopy observations. With one exception, in a case where the canopy was partially defoliated, the simulated canopy input compared favorably with observations.

It is also possible to adapt forecasts to a canopy environment using the Anderson approach. We are experimenting with a more complex forecast technique, the CMFS (61). The CMFS is a one-dimensional (1-D) canopy model that is coupled to the mesoscale model (Fig. 3). The 1-D vertical model is a column of points from the upper portion of the soil to the lower stratosphere. It utilizes the same equations as the three-dimensional (3-D) mesoscale model, but since only vertical processes are included it can have high vertical resolution (on the order of $1 \mathrm{~m}$ ). The 1-D model incorporates sitespecific information for parameters - such 
as surface heat capacity, albedo, and leaf area index-that cannot be included in the 3D model because of its much coarser horizontal resolution.

In our experience with a grape canopy, the CMFS alone did not improve upon the more simplistic LMFS. The reasons for this weak performance could be nonsystematic errors related to atmospheric phenomena (37) such as cloud cover and systematic errors in the partitioning of energy within the canopy and soil (20). Even with its shortcomings, the CMFS proved to be a valuable stepping-stone toward the development of canopy-specific data. It may be instructive to discuss how the CMFS, beginning as an experimental model, became incorporated into a commercial application.

During the late 1990s, SkyBit researchers, in cooperation with one of the authors at the Rutgers Blueberry and Cranberry Research Center (Chatsworth, NJ) and growers in southern New Jersey, were designing a sitespecific weather product for the cranberry industry (Fig. 4) (61). The numerical modeling system in place at the time did not provide satisfactory forecasts for either frost events or heat stress. The shortcomings in the forecasts were narrowed down to the cranberry canopy environment, which was quite different from the "standard" setting of short-cut grass, open fetch, and a sloping surface used for the then-existing, sitespecific weather products. Cranberries are grown on a sandy surface and form a continuous canopy approximately 15 to $30 \mathrm{~cm}$ thick. The beds are generally surrounded by dikes that are $1.5 \mathrm{~m}$ in height to allow periodic flooding for harvest and overwintering. The low heat retention by the canopy coupled with the dikes that impede air movement result in a unique microenvironment. The uniqueness of the cranberry canopy environment was accounted for in an "ensemble" approach, which combined output from the CMFS model with output from an empirical canopy model to create a "canopyspecific" product. The canopy-specific product became known as the "Cranberry Canopy Forecast."

An example of the Cranberry Canopy Forecast product is shown in Figure 5 (50). It was generated during the 2001 growing season for a research site in rural New Jersey. The product is divided into three sections: a graph of hourly and three-hourly weather data at the canopy scale, a table containing canopy variables, and a second table containing local weather variables. The graph and first table in the product contain canopy-specific data generated by the ensemble approach. Included among the variables in the first table are disease predictions for root rot and fruit rot. The canopyspecific data were used as input into separate disease models to create forecasts of hours of root rot (Phytophthora cinnamomi) and percentages of fruit rot (Physalospora vaccinii, Coleophoma empetri,
Phyllosticta vaccinii, and Colletotrichum gloeosporioides).

The Cranberry Canopy Forecast product was evaluated during the 2000 and 2001 growing seasons by researchers and cranberry growers (P. V. Oudemans, personal communication). The evaluation had several objectives. One objective was to document the improvement in the accuracy of the temperature forecasts. A second objective was to collect disease and fruit observations in order to refine some preliminary model designs for fruit rot, root rot, and keeping quality. The initial disease model designs were based on published data from studies in the 1930s and 1940s (38). Additional data were needed to "fine tune" the initial designs to the canopy scale and today's land use and crop management practices. A third objective was to get grower feedback on the use of the Forecast product as a management tool. It became evident by the second season of the evaluation that the growers were beginning to rely upon the product for their management decision making. The Cranberry Canopy Forecast is an excellent illustration of how research can be targeted to

\section{E-Weather Cranberry Canopy Forecast}

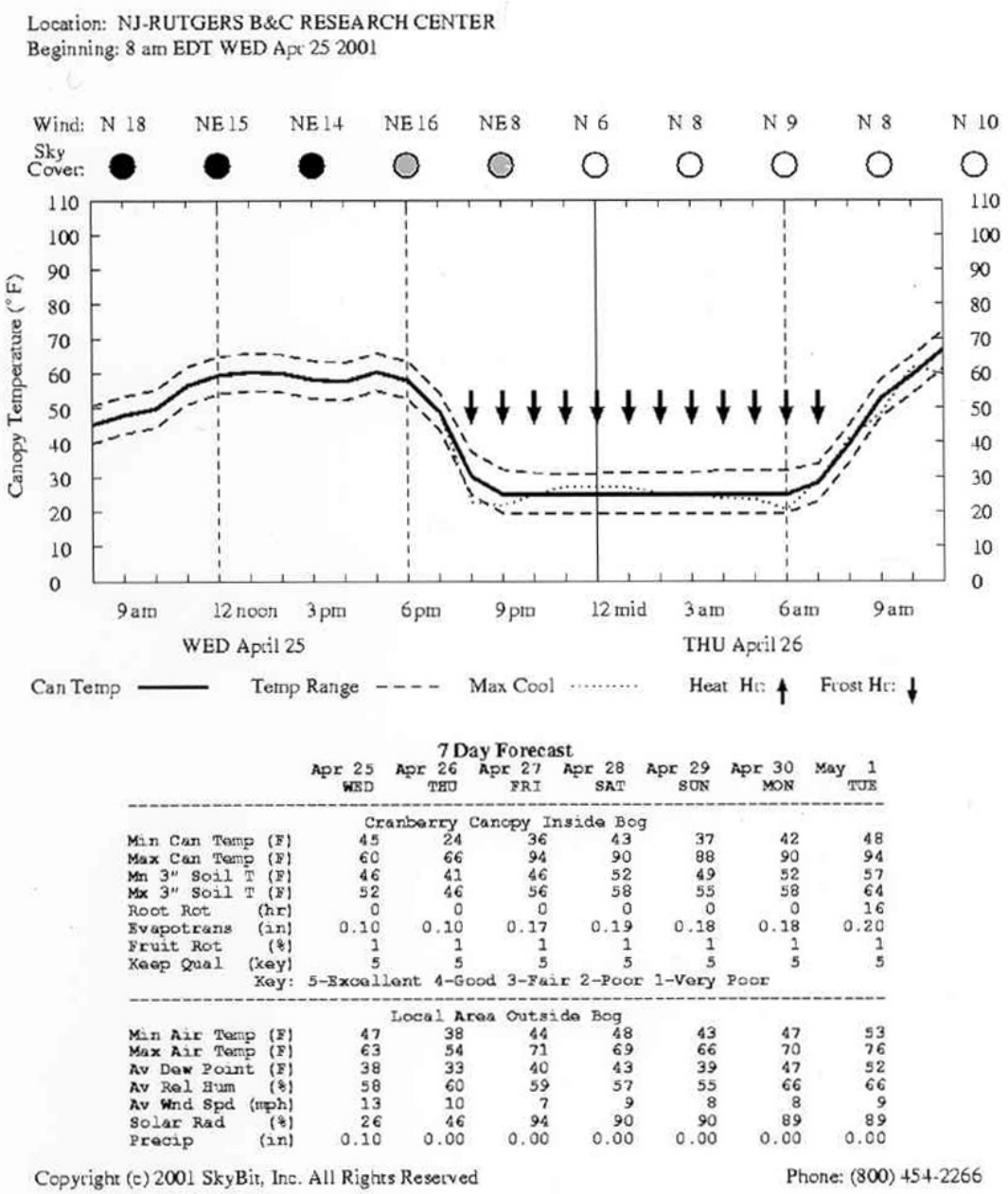

Fig. 5. SkyBit's E-Weather Cranberry Canopy Forecast Product (after Russo and Zack, 50). specific forecasting service.

For many applications, forecast information does not need to be as accurate as observations. For example, our observations of the accuracy of E-Weather (LMFS) temperature forecasts are that as the forecast period increases, the accuracy declines but overall similar trends are still detected (Fig. 6). Growers and other agriinformation for planning purposes such as the deployment of personnel. Knowing that a frost event or infection period is likely, schedules can be rearranged to accommodate the recommended treatments.

\section{Uncertainties Associated with Site-Specific Weather Data}

In this section, we will examine the uncertainties associated with site-specific weather data. An introduction to uncertainty terminology is included as a sidebar. The level of uncertainty required for decision making for plant pathological applications has not been well defined. We have previously suggested the following limits: temperature $\left( \pm 1^{\circ} \mathrm{C}\right)$, relative humidity improve a particular component of a sitecultural professionals may also utilize this 
$( \pm 3 \%)$, rainfall $( \pm 5 \%)(29)$, and $2 \mathrm{~h}$ for surface wetness duration. This limit for surface wetness duration is based on the fact that the precision (95\% confidence limit) for a commonly used sensor (Model 237, Campbell Scientific, Inc., Logan, UT) is about $2 \mathrm{~h}(27,42)$. In reality, errors can sometimes be much larger without changing a management recommendation. This is because the atmospheric requirements for most pathogens are comparatively broad. For example, infection by Venturia inaequalis, causal agent of apple scab, occurs across a relatively broad temperature range from 2 to $>30^{\circ} \mathrm{C}$ (56). The surface wetness requirement varies from $35 \mathrm{~h}$ at $2^{\circ} \mathrm{C}$ to $6 \mathrm{~h}$ at 16 to $24^{\circ} \mathrm{C}(14,56)$. However, once the minimum hours of surface wetness are exceeded, host phenology is more important than additional wetting in determining the severity of the disease (14).
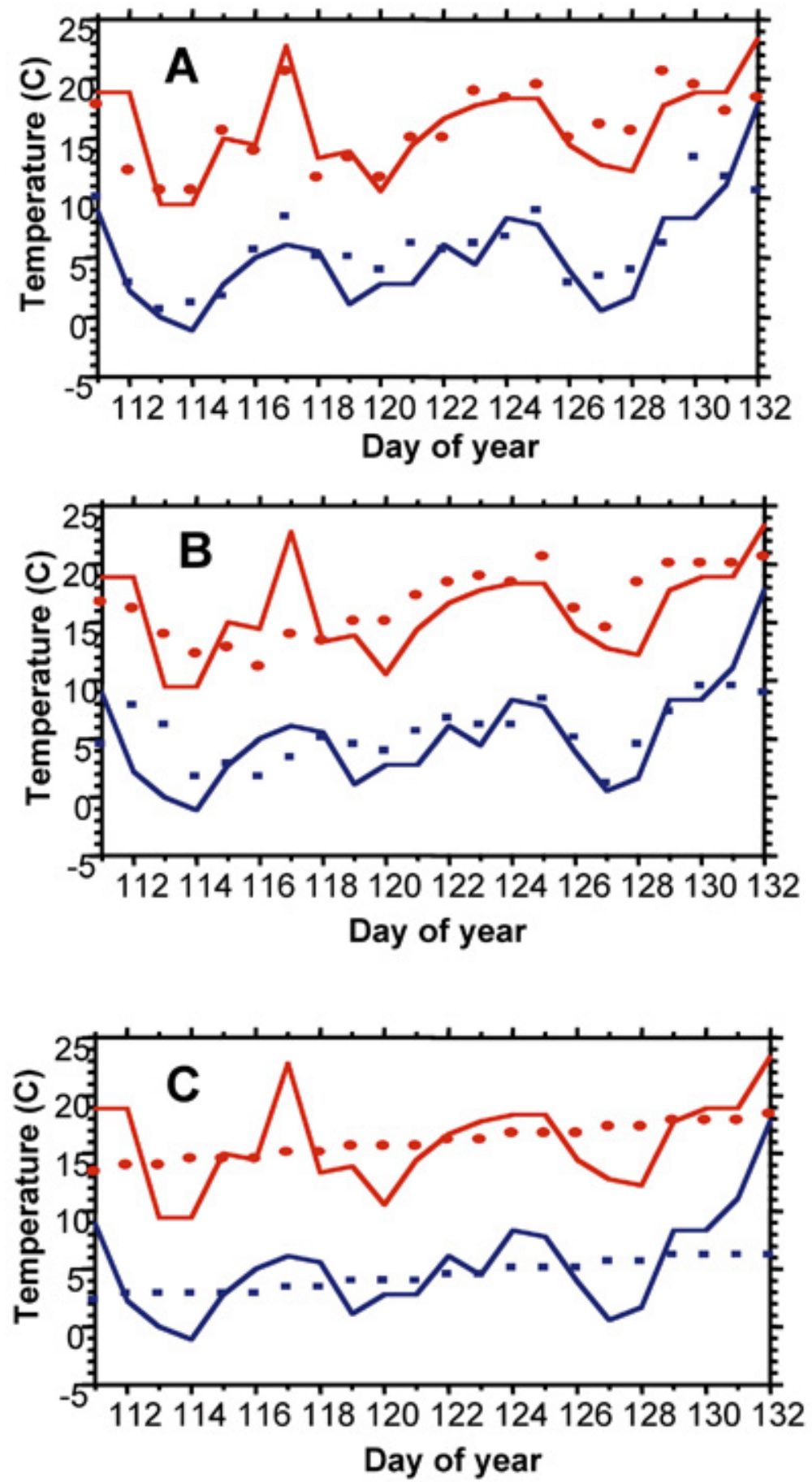

Fig. 6. Observed maximum $(-)$ and minimum $(-)$ temperature in Geneva, NY, during 21 April to 11 May 1995 compared with simulated maximum ( $\bullet$ ) and minimum (G) temperature for: A, 24-h, B, 5-day, and C, 10-day forecasts. (R. C. Seem, unpublished data)

It is apparent that a well-maintained automated weather station (AWS) is likely to be the most certain method of estimating site-specific weather data. Typical instrument errors are likely to be close to the range suggested above (4). However, there are several protocol shortcomings that greatly compromise the performance of grower-operated AWS. The first is the use of the AWS by meteorologically untrained personnel, as is the case with most grower AWS. The second is a failure to calibrate sensors on a regular basis. Sensors should be calibrated at least once per season, but in practice this is the exception rather than the rule. In one study, a relative humidity sensor developed at least a $3 \%$ bias over a 60-day measurement period (1). The third protocol shortcoming is that an AWS may be poorly sited, for example underneath a tree or too close to buildings. The fourth is that an interruption in the operation of an AWS is usually discovered by a failure to record data. In the case where data are being accumulated during a season, even a short-period loss could be critical for the accurate tracking of disease development. This consideration is also applicable to a lesser extent to site-specific weather products. The fifth and final protocol shortcoming has to do with the measurement differences associated with the different brands of AWSs. In an evaluation of AWSs for use in a decision support system (59), it was observed that although temperature and relative humidity information provided were similar, surface wetness and precipitation were variable between instruments. The problems associated with surface wetness will be discussed later.

In recent years, as analytical techniques for creating data have become more accepted, there have been an increasing number of evaluations of the accuracy of simulated observations and forecasts $(13,17,18,60)$. Site-specific data accuracy, as quantified by statistical techniques, depends on the variable, location, season, and surface cover. Like regional AWS networks, the performance of analytical techniques is dependent upon the density of observations, which in some areas is low. For example, within the Finger Lakes region of New York State, there are approximately 700,000 ha in all land use categories, but only about six NWS or FAA weather observing stations. Sitespecific data for continuous variables, such as temperature and radiation, are good to excellent, while data for discontinuous variables, such as precipitation and cloud cover, are poor to fair. With continuous variables, the phenomena of persistence allows the next value in time series to be estimated with greater confidence. In formal comparisons with local measurements, the accuracy of simulated hourly observations over a 3-year period in New York State was close to $1^{\circ} \mathrm{C}$ for temperature and $7 \%$ for relative humidity (Table 1) (27). 
Results from another study are similar (17). A potato canopy model run from simulated observations was assessed for its ability to predict events of high (>90\%) relative humidity (1). The model was able to predict high relative humidity events within $1 \mathrm{~h}$ on $83 \%$ of occasions. For some applications, daily data are required and errors are generally lower than for hourly data. For example, errors in simulated daily average temperature were as low as $0.2^{\circ} \mathrm{C}(17)$.

While the accuracy of simulated observations is fair to good, forecasts are less accurate. In a study that evaluated 24 -h forecasts and simulated observations to measured values, additional errors of $0.3^{\circ} \mathrm{C}$ for air temperature and $3 \%$ for relative humidity were found in the forecasts when compared with simulated observations (27).

\section{Applications of Site-Specific Weather Data}

There are several published examples of the use of site-specific weather simulators for pest and disease prediction, including apple pests and diseases, potato late blight, soybean rust, grapevine downy mildew, and gypsy moth $(13,45,48,49)$. One important application of site-specific weather is regional mapping (58), which can be a powerful tool for decision making or raising public awareness (Fig. 8). However, the main application for site-specific weather data is its role in fueling decision support systems $(13,46)$. Truxall and Travis (60) found that the use of mesoscalederived predictions would rarely result in an incorrect decision in apple disease management. Simulated observations provide a powerful means for eliminating the necessity for an on-site AWS to run a decision support system and for freeing the user from the burdens of maintaining and downloading AWS data. The importance of this will be discussed in a companion feature article (31).

Site-specific weather data created by spatial interpolation can be a powerful analytical tool to assess the suitability of a new cultivar at a given site. In one regional assessment, relationships were first developed between yield and local weather conditions for a given cultivar. Site-specific climate data were then used at one location to determine the frequency of unfavorable and favorable weather conditions at that site and the likely yields of the given cultivar (J. M. Russo, unpublished data). This analytical approach has obvious potential

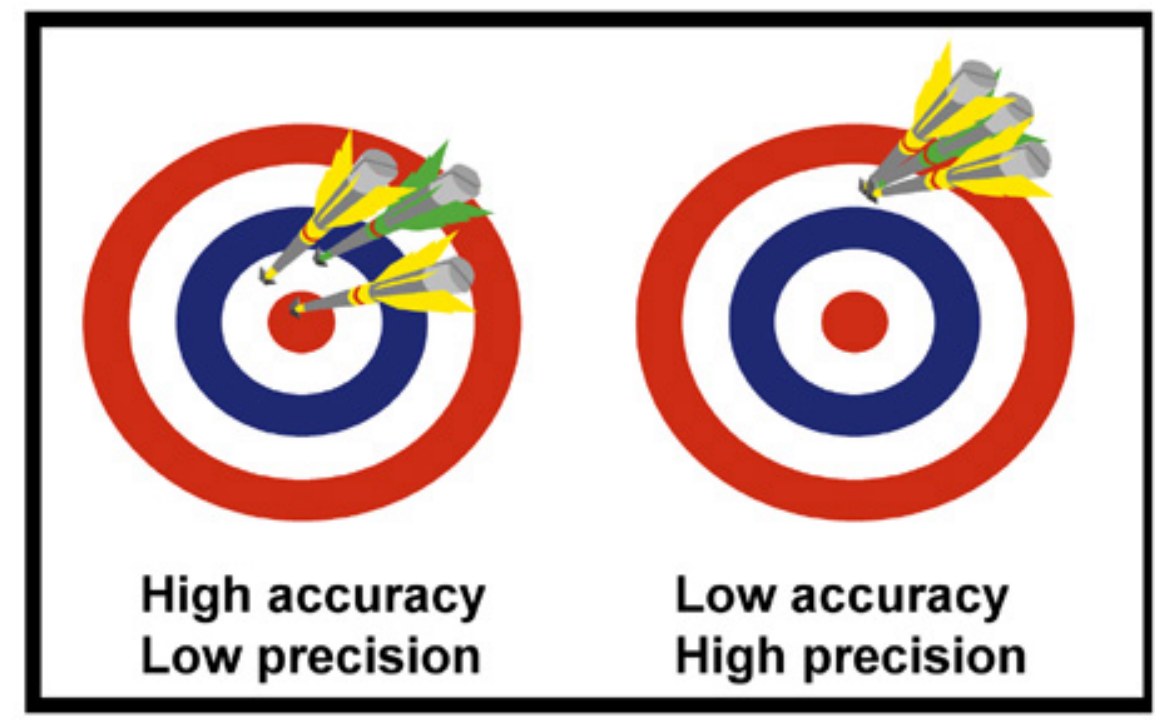

Fig. 7. Graphical illustration of precision and accuracy. for assessing disease resistance of a new cultivar. Another application of sitespecific weather is in the determination of the potential distribution of exotic pests under current or future climate scenarios $(5,45)$. Another useful application for the mesoscale forecast systems is to provide high spatial resolution for climate change studies (52).

Surface wetness or leaf wetness requires special attention because of the difficulties associated with its measurement and because of its importance in plant pathology $(18,23,26,57)$. It also varies greatly depending upon microclimate. At present, surface wetness duration on plant surfaces is measured indirectly with either electronic (Fig. 9) or mechanical sensors (57).

\section{Sidebar 1: Spatial Scales and Weather Information}

Weather information must be considered in the context of both spatial and temporal scales (54). For site-specific agriculture and disease forecasting purposes, we are primarily interested in spatial scales between $1 \mathrm{~km}$ and $1 \mathrm{~m}$ and in temporal scales that represent climatic, current, and forecast data (Fig. 1, white-dotted box). Historically, there has been a gap between what users want and what information is available. Weather observations collected by national and state weather networks are usually at a spatial scale too coarse for sitespecific uses. Although research and private on-farm automated weather stations (AWS) could provide us with sitespecific data, these stations often have limited life spans or uncertain quality assurance procedures. Like observations, forecast weather information produced by national weather services is usually considerably cruder than agricultural districts or farms. Even when networks are in place, data must be extrapolated for sites distant from a station. During the last 10 years, there has been a dramatic improvement in the availability of site-specific weather data. In this article, we track the evolution of the analytic tools that have made this improvement possible.

\section{Sidebar 2: Errors and Uncertainties Associated with Weather Data}

No measurement is complete unless it includes an estimate of the probable magnitude of the uncertainty (3). Weather information regardless of whether it is collected on-site or estimated remotely is subject to uncertainty. Unlike error, uncertainty is not correctable. The total uncertainty can be written as the sum of the uncertainties due to precision, accuracy, protocol, and scale $(3,36,47)$. Precision can be defined as the closeness of agreement between independent measurements of a single quantity obtained by applying a stated measurement procedure several times under prescribed conditions. Accuracy is the extent to which a measurement agrees with the true value and assumes that all known corrections have been applied. Using an analogy of a dart player, accuracy is how close the arrows are to the bull's-eye, while precision is how tightly clustered the arrows are, regardless of their position relative to the bull's-eye (Fig. 7) (36). Protocol is the uncertainty that arises when an instrument is used with different observers or methodologies for measurement. The uncertainty due to scale is associated with variability of a phenomenon over a defined space and time. For example, leaf wetness may be measured at a single location in the canopy, but fungicide treatments are applied to a whole field. 
Table 1. Comparison of errors between two site-specific weather simulators and observed data at $1 \mathrm{~m}$ above the top of a grape canopy over a 17 day period in September 1996 at Geneva, NY. The two simulators were the Localized Mesoscale Forecast System (LMFS) and Canopy Mesoscale Forecast System (CMFS) (52)

\begin{tabular}{llccccccc}
\hline & \multicolumn{2}{c}{ Temperature $\left({ }^{\circ} \mathbf{C}\right)$} & \multicolumn{2}{c}{ Relative humidity $(\boldsymbol{\%})$} & \multicolumn{2}{c}{ Wind speed (m/s) } & \multicolumn{2}{c}{ Rain $^{\mathbf{a}}(\mathbf{h})$} \\
\hline LMFS & 1.4 & $(0.1)$ & 7.9 & $(-3.4)$ & 0.8 & 0.3 & 2.8 & 2.2 \\
CMFS & 2.1 & $(-1.4)$ & 7.1 & $(2.1)$ & 0.6 & 0.8 & 0.0 & 1.8 \\
\hline
\end{tabular}

a Rain hours only.

b The mean relative error was calculated from the arithmetic average of the predicted-observed.

c The mean absolute error was the arithmetic average of the absolute value of the differences between the predicted-observed.

\section{Grapevine powdery mildew forecast}

\section{Based on $1 \mathrm{~km}, 24-\mathrm{hr}$ weather forecast}

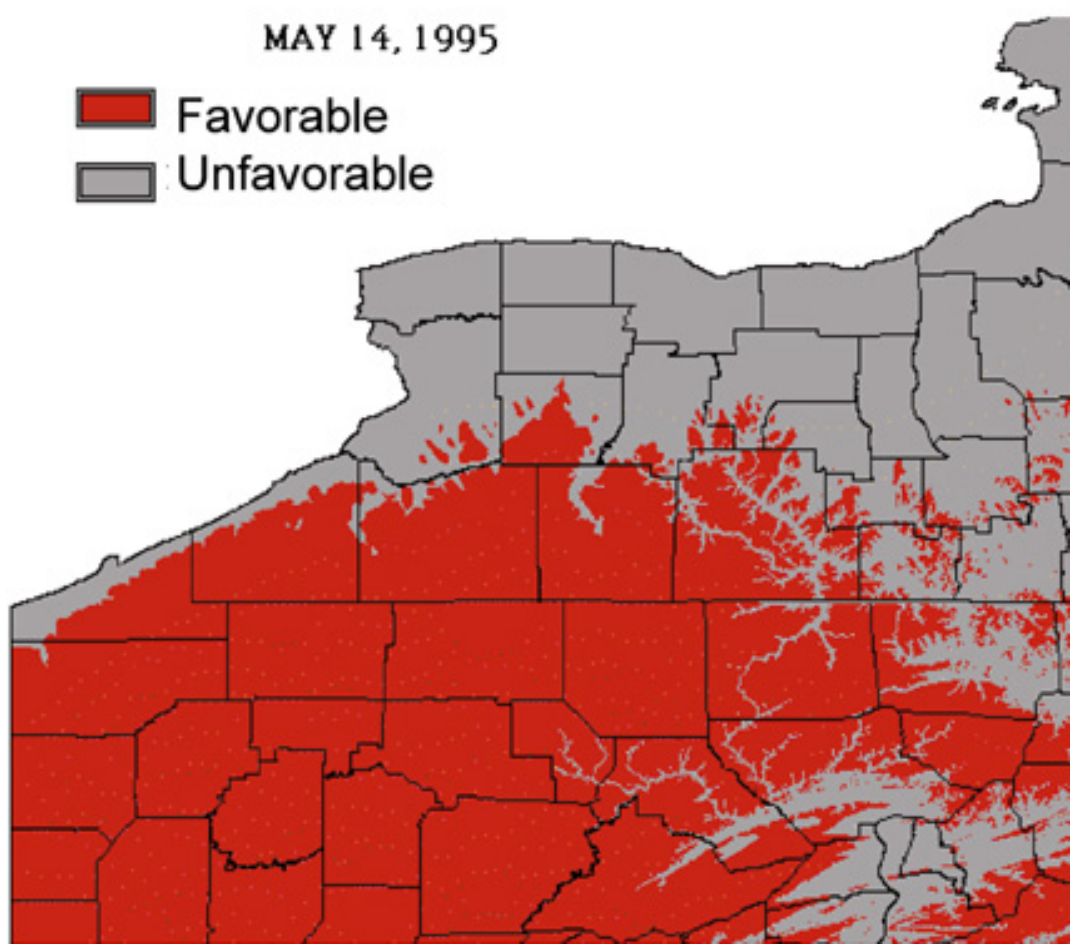

Fig. 8. Forecast of grape powdery mildew for 14 May 1995 made on 13 May 1995 using the Localized Mesoscale Forecast System (LMFS) weather forecasts and ascosporic infection rules $\left(>10^{\circ} \mathrm{C}\right.$ and $>2.5 \mathrm{~mm}$ rainfall). The forecast map represents western New York and northwestern Pennsylvania. (R. C. Seem, unpublished data)

Unfortunately, these sensors often have low accuracy and precision $(27,42)$, so the development of an alternative to on-site instruments is highly desirable. One promising alternative is a surface wetness model (23,27). Unlike an on-site AWS, a surface wetness model can use simulated inputs of temperature, precipitation, relative humidity, evaporation, wind speed, incoming short-wave radiation, and outgoing longwave radiation, to estimate wetness duration.

The ability of models, using site-specific weather data as input, to estimate surface wetness is improving and in some cases is close to that of sensors $(17,18,27)$. Magarey (27) found that simulated observations of surface wetness (E-Weather) were as effective as measurements made by sensors when compared with visual observations. Gleason et al. (18) found that simulated observations of surface wetness (EWeather) underestimated measured surface wetness by $2.0 \mathrm{~h} /$ day. This result should be interpreted in view that sensors have a $95 \%$ uncertainty close to $2 \mathrm{~h}$ (27).

By using a surface wetness model, it is also possible to estimate surface wetness in forecast mode. Since the uncertainties associated with the weather inputs are

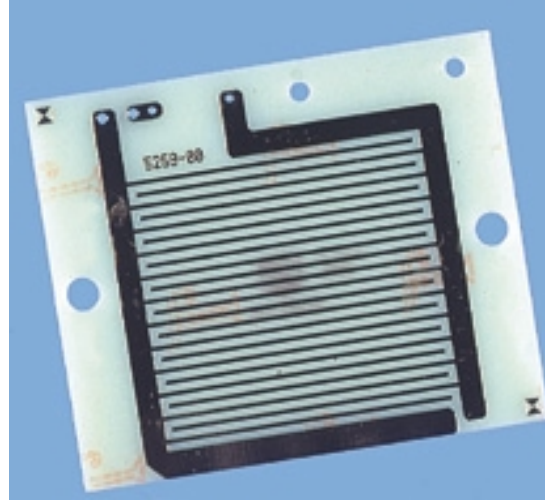

Fig. 9. A surface wetness sensor based on an electronic circuit board design.

higher for forecast data than for simulated observations, the surface wetness estimates are less reliable (27), although they can still capture the general trends (Fig. 10) (52). However, a lower accuracy does not mean that the surface wetness forecasts are less useful to farmers than observations. Forecasts can capture the general trend in canopy surface wetness. In addition, it is possible to adapt raw surface wetness data to a categorical forecast of days with possible infection periods (51). Estimation of site-specific surface wetness data from climate records can also be quite useful, but has rarely been used. Bass et al. (6) developed a methodology to predict the likely occurrence of southern corn leaf blight from climate data. The lack of available surface wetness measurements was overcome by using a surface wetness model to estimate wetness periods. A Gumbel distribution was then used to estimate the probability of a 24-h episode of surface wetness occurring at any given site.

\section{Outlook: Precision Agriculture, New Sensors, and Free Data}

So far, we have discussed weather information that simply represents a point, as in the case of an AWS, or is estimated at scales often much larger than $1 \mathrm{~km}^{2}$. We will now consider how weather data can be estimated at much finer spatial scales. Although a point or a $1 \mathrm{~km}^{2}$ area is a suitable scale for many agricultural applications, there can be great variability in weather within a distance of less than $1 \mathrm{~km}$. First, there is variation caused by small-scale atmospheric phenomena such as isolated 
thunderstorms. Second, weather variables may be greatly influenced by topography and the proximity to lakes or small bodies of water. For example, Bootsma (11), investigating topographical temperature variation, found that on relatively clear calm nights, base-station minus site minimum temperature averaged $1^{\circ} \mathrm{C}$ on hilltops, 2 to $3^{\circ} \mathrm{C}$ midway down slopes, and 5 to $6^{\circ} \mathrm{C}$ in hollows. Clarke (12), investigating freezing injury in cherries, noticed differences of 1 to $4^{\circ} \mathrm{C}$ in minimum temperatures between two orchards $1 \mathrm{~km}$ apart. In another study, freezing injury to cherries varied from almost none to severe in a distance of $70 \mathrm{~m}$ on a sloping site near Kaiserstuhl, Germany (15). Lakes also may have a large influence on temperatures and consequently on relative humidity and surface wetness. For example, in New York State, we found that sites in close proximity to Seneca Lake had minimum temperatures up to $5^{\circ} \mathrm{C}$ greater during winter than sites less than $1 \mathrm{~km}$ distant from the lake (30). In contrast to temperature, there have been few studies of the spatial variability of surface wetness. One example is Penrose and Nicol, who found that orchards within a $5-\mathrm{km}$ radius had the same total hours of leaf wetness, but one $20 \mathrm{~km}$ away did not (40).

The need for fine-scale weather data is not an academic exercise. The increasing use of precision agriculture creates the need to map environmental variation at the subfield scale $(39,41)$. The five main processes in precision agriculture are spatial referencing, differential action, crop, soil, and climate monitoring, attribute mapping, and decision support systems. Whereas in conventional agriculture, variable rate applications may be made to whole fields many hectares in size, in precision agriculture it is possible to apply variable rates to plots as small as a square meter. Unfortunately, fine-scale maps of weather variables can be extremely difficult to produce. These difficulties are due to computer processing speeds, uncertainties in atmospheric inputs, and limitations in surface databases. Each of these difficulties will be discussed in more detail.

The computer processing speed difficulty is tied to scale. Processing time increases exponentially as one moves to finer scales. A one-order change in spatial scale (i.e., $1 \mathrm{~km}^{2}$ to $1 \mathrm{ha}$ ) results in a 1,000 -fold increase in the potential number of calculations due to the increased number of grid points and a shorter calculation time-step. If the desired scale was that of an individual plant, say $1 \mathrm{~m}^{2}$, then there could be another $1 \times 10^{6}$-fold increase in the number of calculations. Another limitation associated with processing, especially if it involves the creation and delivery of products, is the narrow time window. Too many steps or calculations will result in late product delivery. In moving to a finer scale, it is necessary to adopt simplifica-

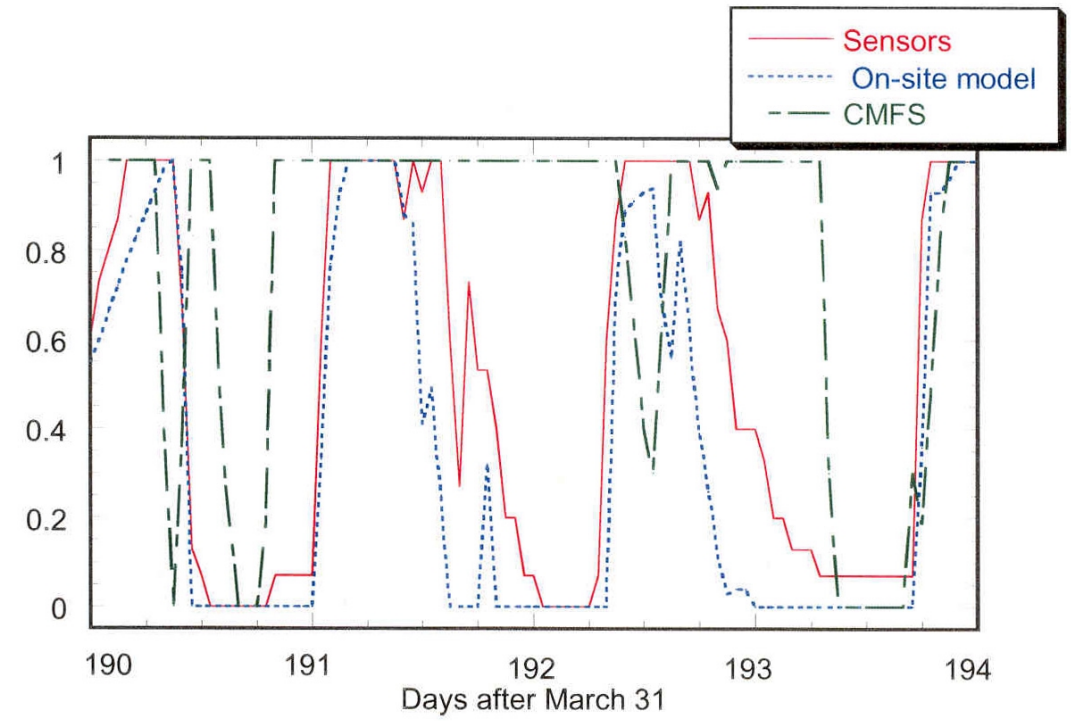

Fig. 10. A comparison of measured and simulated proportion of surface area wet in a grape canopy over a 5-day period. On-site sensors provided direct reading of wetness while a whole plant canopy model provided on-site estimates and Canopy-Mesoscale Forecast System (CMFS) provided site-specific estimates (52).

tions or shortcuts. One approach is to simplify the atmospheric physics to enable a more rapid execution. Our group has been experimenting with a Local-Area Weather Simulation System (LAWSS), which is a simplified version of the MASS mesoscale model (30). The LAWSS model uses some of the assumptions of Mass and Dempsey to simplify the atmospheric physics (34). For example, only the portion of the atmosphere close to the surface of the earth is explicitly simulated. The only data requirements to run LAWSS are upper atmospheric soundings, digital topography, and land use information. It can also be easily run from the output of a mesoscale model.

We compared LAWSS output to results of an interpolation procedure that used two data sources (30). The first source was a local temperature logger network, and the second was the National Weather Service (NWS). The former had 22 loggers within the Finger Lakes area compared with six NWS stations. Output from the LAWSS model had a similar accuracy to the spatial interpolations made from the two sets of temperature network data. However, LAWSS did not require any additional local weather data other than the upper air data. The results of the spatial interpolations tended to exhibit too much smoothing, whereas the LAWSS output was able to capture local-scale variation. For example, LAWSS was able to detect the influence of the Finger Lakes on the local environment. This influence was completely missed by the interpolated data.

Although we believe the LAWSS model represents an improvement upon existing techniques, it is still relatively slow. About $13 \mathrm{~h}$ of processing time is required to run a $10 \mathrm{~km}^{2}$ area at a 4-ha grid size on a mid- range workstation. However, if Moore's law, which dictates that computing power will double every 18 months, holds true, then LAWSS could see routine real time use for disease forecasts within 10 years. In the meantime, we see LAWSS being used for applications such as site selection. For example, LAWSS is currently being used to estimate the susceptibility of vineyard sites to extreme winter weather.

The second difficulty, that of uncertainties in weather input (37), prohibits the extrapolation or simulations being made at a fine scale. As previously discussed, one problem is low station density. This problem may be alleviated with the assistance of remote sensing technologies. For example, Doppler radar has been used to provide precipitation estimates in the forecasting of peanut diseases (19). The study found that there was no difference in the number of applications made for disease control between the advisories made by the Doppler radar and the on-site AWS. In another example, satellite images could provide cloud cover estimates for surface energy balance calculations.

The final difficulty involves surface databases. As weather simulations and forecasts improve in spatial resolution, similarscale data are needed for elevation, soil attributes, land cover, land use, and other surface properties. In recent years, finer scale databases have become more widely available. For example, the Cornell University Geographic Information Resource (CUGIR) is one of two repositories of free spatial information for New York State. Much of this information is now available at the farm scale, including digital orthoquads at a $1-\mathrm{m}$ resolution. Although georeferenced digital farm maps are expensive to construct (7), advances in global posi- 
tioning system (GPS) and geographic information system (GIS) technologies will eventually remove these cost barriers. In particular, the common object modeling (COM) approach allows a high degree of interoperability between GIS, atmospheric, and future disease forecast models (9). In other words, disease models could be "plugged and played" into a spatial decision support system.

Site-specific weather simulators will not be the only exciting development. We also look forward to the next generation of sensors. It is too early to anticipate the exact design of these sensors, but we expect them to be constructed with nanofabrication technology (21). This could enable several sensors to be placed onto an instrument the size of a pinhead. They are likely to be both biodegradable and disposable. A large number of sensors could be placed uniformly through a field or even on mobile drones. The sensors communicate via a radio-telemetry link to a base station providing a high-resolution picture of an individual field. Although the pinhead technology is likely to be decades away, nanoscale technology is likely to make a significant contribution to the construction of better and lower cost sensors within 10 years.

One future development that is just getting underway is the merging of sitespecific weather technologies. For example, an on-site AWS can report observations back to a base station. At the base station, the observations are compared with simulations. The observations can then be used to fine-tune or calibrate the simulations, or the simulations may flag that a station or sensor requires maintenance or recalibration. Whatever technologies are used to provide site-specific weather data, it is important that there is little demand placed on growers' time.

The availability of data will continue to increase in the future. In some cases, the data will be free. For example, due to the intense competition between commercial weather providers and the increase in computing power, weather data are slowly becoming a free information commodity. Data for some popular weather variables are given away at web portals to increase advertising revenues by attracting "hits." This will be true only to a certain extent. We anticipate that weather companies will make some of their revenues by providing forecasts and climate information to subscribers at finer spatial $\left(<1 \mathrm{~km}^{2}\right)$ and temporal $(<1 \mathrm{~h})$ scales. Other commercial revenues will be found in "value-added" products (i.e., disease predictions).

While large amounts of data will be available for decision making in the future, a note of caution is in order. It is comparatively easy for non-plant pathologists to create value-added products, such as disease warnings. All that is required is some back copies of Phytopathology and the inclusion of a few extra algorithms into the output of the atmospheric models. Such an approach can often create information that can loosely be termed "junk data." To determine whether these warnings are actually meaningful requires an interdisciplinary team of scientists and growers, and years of testing. This often-painful process of evaluation adds real value to a product. This value adding cannot be easily seen in fancy graphs or maps of disease risk. However, junk data are not the only problem associated with new technologies. In another feature article, we will take an overall look at decision support systems, including the important role of site-specific weather information (31).

\section{Literature Cited}

1. Anderson, M. C., Bland, W. L., Norman, J. M., and Diak, G. D. 2001. Canopy wetness and humidity prediction using satellite and synoptic-scale meteorological observations. Plant Dis. 85:1018-1026.

2. Anderson, M. C., Norman, J. M., Meyers, T. P., and Diak, G. D. 2000. An analytical model for estimating canopy transpiration and carbon assimilation fluxes based on canopy light-use efficiency. Agric. For. Meteorol. 101:265-289.

3. Anonymous. 1983. Guide to Meteorological Instruments and Methods of Observation. World Meteorological Organization, Geneva, Switzerland.

4. Anonymous 1996. CR10X Reference Manual. Campbell Scientific, Logan, UT.

5. Baker, R. H. A., Sansford, C. E., Jarvis, C. H., Cannon, R. J. C., MacLeod, A., and Walters, K. F. A. 2000. The role of climatic mapping in predicting the potential distribution of nonindigenous pests under current and future climates. Agric. Ecosys. Environ. 82:57-71.

6. Bass, B., Savdie, I., and Gillespie, T. J. 1991. Simulation of leaf wetness duration for field corn. Agric. For. Meteorol. 57:69-84.

7. Beck, H., Albrigo, G., Wheaton, A., Castle, B., Zazueta, F., Peart, B., Ferguson, J., and Martsolf, D. 1998. Decision information systems for citrus. Pages 495-501 in: Seventh International Congress on Computers in Agriculture. American Society of Agricultural Engineers, St. Joseph, MI.

8. Beck, H., and Jackson, J. 1998. Florida automated weather network. Pages 595-601 in: Seventh International Congress on Computers in Agriculture. American Society of Agricultural Engineers, St Joseph, MI.

9. Bernard, L., and Kruger, T. 2000. Integration of GIS and spatio-temporal simulation models: Interoperable components for different simulation strategies. Trans. GIS. 4:197-215.

10. Bingham, G. E., McCurdy, G. D., and Hill, R. W. 1992. Real-time weather systems in agricultural support: The loop is closed - or is it? Acta Hortic. 313:271-283.

11. Bootsma, A. 1976. Estimating minimum temperature and climatological freeze risk in hilly terrain. Agric. Meteorol. 16:425-443.

12. Clarke, W. S. 1941. Temperature differences within an orchard and their effects on fruit. Proc. Am. Soc. Hortic. Sci. 39:25-30.

13. Felland, C. M., Travis, J. W., Russo, J. M., Kleiner, W. C., and Rajotte, E. G. 1997. Validation of site-specific weather data for insect phenology and disease development in Pennsylvania apple orchards. PA. Fruit News 77:10-17.

14. Gadoury, D. M., Seem, R. C., Stensvand, A., and Falk, S. P. 1996. Minimum criteria for infection by Venturia inaequalis, and severity of scab at different phenological stages of apple. (Abstr.) Phytopathology 86:S122.

15. Geiger, R. 1965. The climate near the ground Harvard University Press, Cambridge, MA.

16. Gillespie, T. J., and Barr, A. 1984. Adaptation of a dew estimation scheme to a new crop and site. Agric. For. Meteorol. 31:289-295.

17. Gleason, M., Koehler, K., and Ryan, K. 1997. SkyBit accuracy evaluation - 1997. Pages 2021 in: Proc. Annu. Tomato Dis. Workshop, 13th. Indianapolis, IN.

18. Gleason, M. L., Parker, S. K., Pitblado, R. E. Latin, R. X., Speranzini, D., Hazzard, R. V., Maletta, M. J., Cowgill, W. P., and Biederstedt, D. L. 1997. Validation of a commercial system for remote estimation of wetness duration. Plant Dis. 81:825-829.

19. Hagan, A. K., Bowen, K. L., Bauske, E. M., Getz, R. R., and Adams, S. D. 1999. Doppler radar precipitation estimates added to AUPnut advisory. (Abstr.) Phytopathology 89:S32.

20. Heilman, J. L., McInnes, K. J., Savage, M. J., Gesch, R. W., and Lascano, R. J. 1994. Soil and energy balance in a west Texas vineyard. Agric. For. Meteorol. 71:99-114.

21. Hoch, H. C., Jelinski, L. W., and Craighead, H., eds. 1996. Nanofabrication and Biosystems: Integrating Materials Science, Engineering and Biology. Cambridge University Press, Cambridge, NY.

22. Hoppmann, D. 1997. The transfer of agrometeorological measurable variables in terrain. Vitic. Enol. Sci. 52:117-119.

23. Hoppmann, D., and Wittich, K. P. 1997. Epidemiology-related modelling of the leaf wetness duration as an alternative to measurements, taking Plasmopara viticola as an example. J. Plant Dis. Prot. 104:533-544.

24. Kelley, J. G. W., Russo, J. M., Eyton, J. R., and Carlson, T. N. 1988. Mesoscale forecasts generated from operational numerical weather-prediction model output. Bull. Am. Meteorol. Soc. 69:7-15.

25. Kuuseoks, E., Liechty, H. O., Reed, D. D., and Dong, J. 1997. Relating site-specific weather data to regional monitoring networks in the lake states. For. Sci. 43:447-452.

26. Lau, Y. F., Gleason, M. L., Zriba, N., Taylor, S. E., and Hinz, P. N. 2000. Effects of coating, deployment angle, and compass orientation on performance of electronic wetness sensors during dew periods. Plant Dis. 84:192-197.

27. Magarey, R. D. 1999. A Theoretical Standard for Estimation of Surface Wetness Duration. Ph.D. thesis. UMI Publications, Ann Arbor, MI.

28. Magarey, R. D., Magarey, P. A., Emmett, R. W., Wachtel, M. F., and Biggins, L. T. 1993 The mildews - some rules of thumb. Aust. Grapegrow. 357:23-24.

29. Magarey, R. D., Magarey, P. A., and Seem, R. 1994. Developing a low cost disease predictor. Aust. Grapegrow. 363:63-65.

30. Magarey, R. D., Seem, R. C., Zack, J. W., Wolf, T., and Martinson, T. E. A high resolution atmospheric model for prediction of winter injury and vineyard site selection. Proc. Int. Sympos. Cool Climate Vitic. Enol., 5th. Melbourne, Victoria, Australia. In press.

31. Magarey, R. D., Travis, J. W., Russo, J. M., Seem, R. W., and Magarey, P. A. Decision Support Systems: Quenching the thirst. Plant Dis. In press.

32. Mahfouf, J., and Jacquemin, B. 1989. A study of rainfall interception using a land surface parameterization for mesoscale meteorological models. J. Appl. Meteorol. 28:12821302.

33. Manobianco, J., Zack, J. W., and Taylor, G. E 1996. Workstation-based real-time mesoscale modeling designed for weather support to operations at the Kennedy Space Center and 
Cape Canaveral Air Station. Bull. Am. Meteorol. Soc. 77:653-672

34. Mass, C. F., and Dempsey, D. P. 1985. A onelevel, mesoscale model for diagnosing surface winds in mountainous and coastal regions. Mon. Weather Rev. 113:1211-1227.

35. Monteith, J. L., and Unsworth, M. H. 1990. Principles of Environmental Physics. Edward Arnold, New York.

36. Moore, D. S. 1985. Statistics, Concepts and Controversies. W. H. Freeman and Company, New York.

37. Nutter, P. A., and Manobianco, J. 1999. Evaluation of the 29-km Eta Model. Part I: Objective verification at three selected stations. Weather Forecast. 14:5-17.

38. Oudemans, P. V., Caruso, F. L., and Stretch, A. W. 1998. Cranberry fruit rot in the Northeast: A complex disease. Plant Dis. 82:1176-1184.

39. Paveley, N. D., Clark, W. S., Sylvester, B. R., Bryson, R. J., and Dampney, P. 1996. Responding to inter- and intra-field variation to optimize foliar disease management in wheat. Pages 1227-1234 in: Brighton Crop Protection Conference: Pests \& Diseases 1996. Vol. 3. Boots Co., Nottingham, UK.

40. Penrose, L. J., and Nicol, H. J. 1996. Aspects of microclimate variation within apple tree canopies and between sites in relation to potential Venturia inaequalis infection. N.Z. J. Crop Hortic. Sci. 24:259-266.

41. Plumb, R. 1997. Bringing Precision to Decisions in Agriculture. Pestic. Outlook 8:29-33.

42. Portratz, K. J., Gleason, M. L., Hockmuth, M. L., Parker, S. K., and Pearston, G. A. 1994. Testing the accuracy and precision of wetness sensors in a tomato field and turfgrass. J. Ia. Acad. Sci. 101:56-60.

43. Rieger, T. 1995. Grower network on-line for better disease control. Vineyard and winery management. March/April, 1995. pp. 41-43.

44. Royer, M. H., Russo, J. M., and Kelley, J. G. W. 1989. Plant disease prediction using a mesoscale weather forecasting technique. Plant Dis. 73:618-624

45. Royer, M. H., and Yang, X. B. 1991. Application of high-resolution weather data to pest risk assessment. EPPO Bull. 21:609-614

46. Russo, J. M. 2000. Weather forecasting for IPM. Pages 453-473 in: Emerging Technologies for Integrated Pest Management: Concepts, Research, and Implementation. G. G. Kennedy and B. Sutton, eds. American Phytopathological Society, St. Paul, MN.
47. Russo, J. M., Bass, D., and Bardosy, A. 1993. Uncertainty analysis of simulated weather information. Pages 11-15 in: BAHC Focus 4: Weather Generator Project. Vol. 1. B. Bass, ed. BAHC Core Project Office. IGPP-ICSU, Institute for Meteorology, Free University, Berlin, Germany.

48. Russo, J. M., Kelley, J. G. W., Seem, R. C., and Travis, J. W. 1989. Vine disease assessment using high resolution forecasts. Page 63 in: Proc. Conf. Agric. For. Meteorol., 19th. American Meteorology Society, Boston, MA.

49. Russo, J. M., Liebhold, A. M., and Kelley, J. G. W. 1993. Mesoscale weather data as input to a gypsy moth (Lepidoptera: Lymantriidae) phenology model. J. Econ. Entomol. 86:838844.

50. Russo, J. M., and Zack, J. W. Commercialization of Plant Disease Forecasting in the United States. In: Information Technology in Plant Pathology. Y. H. Kim and E. W. Park, ed. Korean Society of Plant Pathology, Seoul, Korea. In press.

51. Scherm, H., Koike, S. T., Laemmlen, F. F., and van Bruggen, A. H. C. 1995. Field evaluation of fungicide spray advisories against lettuce downy mildew (Bremia lactu-

\section{R. D. Magarey}

Dr. Magarey is a scientific consultant based in Adelaide, Australia. He received his B.Agric.Sci. from Adelaide University in 1989 and a Ph.D. from Cornell University in 1999. His Ph.D. research focused on the simulation and measurement of leaf surface wetness. Between 1990 and 1994, he worked as a plant pathologist for the Victorian Department of Agriculture, specializing in grape diseases. His other research interests include decision support systems and microclimate modeling.

\section{R. C. Seem}

Dr. Seem is professor of plant pathology and associate director of Cornell University's New York State Agricultural Experiment Station (NYSAES). He received a B.S. degree in botany in 1970, an M.S. in plant pathology in 1972, and a Ph.D. in plant pathology in 1976. All degrees were from the Pennsylvania State University. In 1975, he joined the NYSAES Department of Plant Pathology, and in 1990, he accepted a half-time appointment as associate director. Dr. Seem studies the epidemiology of fruit and vegetable diseases with special emphasis on grape downy and powdery mildew and apple scab. He also studies the effects of environment and spatial scale on disease development.

\section{J. M. Russo}

Dr. Russo is president and senior research scientist at ZedX Inc. and SkyBit, Inc. ZedX is an information technology company that specializes in custom weather databases and decision support algorithms for the agricultural and environmental industries. SkyBit specializes in the electronic delivery of sitespecific weather data and weather-dependent products to agricultural and energy industries. Dr. Russo is responsible for the design and development of products within both companies. Prior to joining industry, Dr. Russo was an assistant professor of agricultural climatology at the Pennsylvania State University from 1981 to 1988 . Dr. Russo received a B.S. in meteorology from St. Louis University in 1971, an M.Sc. in meteorology from McGill University in 1974, and a Ph.D. in agricultural meteorology from Cornell University in 1978.

\section{J. W. Zack}

Dr. Zack is president and a senior research scientist at MESO, Inc., a small company based in Troy, NY, which specializes in the development and application of atmospheric numerical models for research and commercial purposes. He has been active in atmospheric model research, development, and application for over 20 years and was one of the original developers of the MASS mesoscale atmospheric model. Dr. Zack received a B.S. in meteorology and oceanography at New York University in 1974, and M.S. and Ph.D. degrees in atmospheric science from Cornell University in 1977 and 1981.

\section{K. T. Waight}

Dr. Waight is a research meteorologist at MESO, Inc., a small company based in Troy, NY, which specializes in numerical modeling of the atmosphere for research and commercial projects. He is currently located in a MESO office at North Carolina State University in Raleigh. His research interests include modeling of the surface energy budget. Dr. Waight received a B.S. in chemistry at Baylor University in 1982, and M.S. and Ph.D. degrees in atmospheric science at the University of Wyoming in 1984 and 1987.

\section{J. W. Travis}

Dr Travis is a professor of plant pathology at the Pennsylvania State University, Fruit Research and Extension Center in Biglerville, PA. He received his B.A. (1975) in biology from Gettysburg College, PA; his M.S. (1978) degree in entomology from the Pennsylvania State University; and his Ph.D. (1981) in plant pathology and horticulture from North Carolina State University. $\mathrm{He}$ has responsibilities in tree fruit and grape extension and research disease management. As part of his educational program for growers, he has worked on the development and implementation of computer based, decision support systems since 1986. He has been a cooperator on the Penn State Apple Orchard Consultant expert system, released in 1991, AusVit, the Australian Viticultural Management expert system released in 1998 and VITIS, grape disease management expert system which is currently being field tested by growers. He has been particularly interested in grower participation in the design, development, and implementation of decision support systems.

\section{P. V. Oudemans}

Dr. Oudemans is an associate professor of plant pathology and extension specialist for blueberry and cranberry diseases at the Philip E. Marucci Center for Blueberry and Cranberry Research and Extension, Rutgers University, Chatsworth, NJ. He earned his M.S. from the University of Guelph, Ontario, in 1986 and his Ph.D. from the University of California, Riverside, in 1990. Dr. Oudemans held a postdoctoral position at Duke University and the University of Kansas before coming to Rutgers in 1993. Previously, he has worked with diseases of onions, avocados, and the white campion as well as pathogens such as Phytophthora and Ustilago. Current research is focused on the biology, etiology, and lifecycles of the many and diverse fungal pathogens of cranberry and blueberry. $\mathrm{He}$ is also working on a collaborative project to use remote sensing for detection and mapping of plant disease in a perennial crop. 
cae) based on measured or forecast morning leaf wetness. Plant Dis. 79:511-516.

52. Seem, R. C., Magarey, R. D., Zack, J. W., and Russo, J. M. 2000. Estimating disease risk at the whole plant level with general circulation models. Environ. Pollut. 108:389-395.

53. Seem, R. C., Magnus, H. A., and Hjonnevaag. 1991. High resolution weather information for plant protection. EPPO Bull. 21:355-364.

54. Seem, R. C., and Russo, J. M. 1983. Predicting the environment. Pages 226-238 in: Challenging problems in plant health. T. Kommedahl and P. H. Williams, eds. American Phytopathological Society, St Paul, MN.

55. Seem, R. C., and Russo, J. M. 1984. Simple decision aids for practical control of pests.
Plant Dis. 68:656-660.

56. Stensvand, A., Gadoury, D. M., Amundsen, T., Semb, L., and Seem, R. C. 1997. Ascospore release and infection of apple leaves by conidia and ascospores of Venturia inaequalis at low temperatures. Phytopathology 87:10461053.

57. Sutton, J. C., Gillespie, T. J., and Hildebrand, P. D. 1984. Monitoring weather factors in relation to plant disease. Plant Dis. 68:78-84.

58. Thomas, C. S., Skinner, P. S., Fox, A. D., Greer, C. A., and Gubler, W. D. Utilization of GIS/GPS based information technology in commercial crop decision making in California. J. Nematol. In press.

59. Truxall, D. L. 1995. An environmentally driven model for grape black rot scouting and the impact of environmental data differences on disease control decision making. Ph.D. thesis. Pennsylvania State University, University Park.

60. Truxall, D. L., and Travis, J. W. 1994. Analysis of the accuracy of predicted weather data on the impact of apple disease management. (Abstr.) Phytopathology 84:1125.

61. Waight, K. T., Young, S. H., and Zack, J. W. 1998. Micrometeorological forecasting with a coupled 3-D mesoscale and one-dimensional boundary layer modeling system. Preprints to the 12th Conference on Numerical Weather Prediction, Phoenix, AZ, American Meteorological Society, Boston, MA. 